\title{
Putting it all together
}

Aggregating impacts of school-feeding programmes on education, health and nutrition: two proposed methodologies

Aulo Gelli, ${ }^{1}$ Francisco Espejo, ${ }^{2}$ Jing Shen, ${ }^{3}$ and Elizabeth Kristjansson ${ }^{4}$

February 2014 
Abstract: School-feeding is an important intervention to attract children to school and augment their learning. The benefits of school-feeding cover several domains. Key to the overall assessment of these benefits is understanding how different implementation models compare to each other and to other interventions with similar aims and objectives. Herein, we outline two approaches to aggregating outcomes for school-feeding. One involves a discreet choice experiment to derive utility scores combining outcomes into one measure. The other focuses on quality-adjusted school days as a measure that encompasses the varied benefits from schoolfeeding. The discrete choice experiment offers a robust method to integrate utility for different benefits. However, it necessitates a complex design. The quality-adjusted school days method has greater simplicity. When developed, different interventions that aim to foster learning could be meaningfully compared.

Keywords: impact, school-feeding, learning, economic indicators

JEL classification: C81, C82, I25

Acknowledgements: Aulo Gelli received support from the Partnership for Child Development at Imperial College and the CGIAR Research Program on Agriculture for Nutrition and Health (A4NH), led by IFPRI. The team's work was supported by UNU-WIDER.

1'International Food Policy Research Institute, agelli@cgiar.org; 2World Food Programme, francisco.espejo@wfp.org; ${ }^{2}$ Institute of Health and Society, Newcastle University, jing.shen@newcastle.ac.uk; ${ }^{4}$ School of Psychology, University of Ottawa, kristjan@uottawa.ca

This study has been prepared within the UNU-WIDER project 'ReCom-Foreign Aid: Research and Communication', directed by Tony Addison and Finn Tarp.

Copyright (C) UNU-WIDER 2014

ISSN 1798-7237 ISBN 978-92-9230-757-8

Typescript prepared by Janis Vehmaan-Kreula at UNU-WIDER.

UNU-WIDER gratefully acknowledges specific programme contributions from the governments of Denmark (Ministry of Foreign Affairs, Danida) and Sweden (Swedish International Development Cooperation Agency-Sida) for ReCom. UNUWIDER also gratefully acknowledges core financial support to its work programme from the governments of Denmark, Finland, Sweden, and the United Kingdom.

The World Institute for Development Economics Research (WIDER) was established by the United Nations University (UNU) as its first research and training centre and started work in Helsinki, Finland in 1985. The Institute undertakes applied research and policy analysis on structural changes affecting the developing and transitional economies, provides a forum for the advocacy of policies leading to robust, equitable and environmentally sustainable growth, and promotes capacity strengthening and training in the field of economic and social policy-making. Work is carried out by staff researchers and visiting scholars in Helsinki and through networks of collaborating scholars and institutions around the world.

UNU-WIDER, Katajanokanlaituri 6 B, 00160 Helsinki, Finland, wider.unu.edu

The views expressed in this publication are those of the author(s). Publication does not imply endorsement by the Institute or the United Nations University, nor by the programme/project sponsors, of any of the views expressed. 
Despite recent progress in addressing the challenges of hunger and undernutrition, according to the FAO, 840 million people were unable to meet the daily nutritional requirements for a healthy life in the years between 2011-13 (FAO 2013). Children who are undernourished often cannot reach their full potential for growth and intellectual development (Walker et al. 2007). Undernutrition can impair cognitive development (Scrimshaw 1998; Worobey and Worobey 1999; Leslie and Jamison 1990) as well as readiness and motivation to learn (Meeks-Gardener et al. 1995). Even short-term hunger can adversely affect attention and interest (Read 1973), while skipping breakfast can impair performance on cognitive tasks, particularly for children who are nutritionally at risk (Pollitt 1995).

School-feeding programmes are designed to support the education of children living in poverty and food insecurity. School-feeding is a simple idea, in practice however, it is a complex intervention with many goals and implementation configurations, involving a broad range of activities by different stakeholders at different levels (Gelli et al. 2012). Its benefits cover several domains of behaviour and learning. The evidence on the impact of school-feeding suggests that, if properly implemented, school-feeding can help to bring children into school and to keep them there, increasing enrolment, reducing absenteeism and drop-out; and that once the children are in school, the programmes can contribute to their learning, through avoiding short-term hunger and enhancing cognitive abilities (see Kristjansson et al. 2007, for a systematic review, and Adelman et al. 2008, for a broader review).

Recently, there has been increased interest in exploring the broader social income generation outcomes linked with the provision of goods and services for school-feeding using 'homegrown' approaches, though the evidence of the benefits is still largely anecdotal and limited to simulation exercises (Espejo et al. 2009).

The review by Kristjansson and her colleagues (2007) and process evaluation by Greenhalgh, Robinson and Kristjansson (2007) highlighted the fact that these simultaneous, multiple outcomes are heterogeneous. Furthermore, they can be context specific and are sensitive to issues of implementation, including the amount of calories offered, type of ration and substitution (replacing some of the food to be received at home). School-feeding implementation modalities include onsite breakfast, lunch or snacks, and/or as take-home rations conditional on school attendance. In terms of relative impact on school participation though, there is little evidence that different school-feeding modalities have different effect sizes. The evidence also suggests that the different modalities have very different costs (Bundy et al. 2009).

The impact of school-feeding in each of the above areas occurs through a number of complex pathways, detailed analysis of which is beyond the scope of this paper and discussed elsewhere (Greenhalgh et al. 2009).

We build this paper on the recent development of the programme theory for school-feeding across education, nutrition, health and other social outcomes (Masset and Gelli 2013). The proposed impact pathways for school-feeding programmes are captured in detail in Figure 3 (Appendix 1). School-feeding programmes can support children's learning in school through two main pathways: The first involves increased access and participation in school (e.g. enrolment, attendance, drop-out) through an incentive, income-transfer effect (Kazianga et al. 2009). The second pathway involves increased learning ability (e.g. attention, cognition) through improved intake of macro- and micronutrients (Adelman et al. 2008; Greenhalgh et al. 2007). 
School-feeding is an important and wide-spread educational intervention; global estimates of programme scale suggest that approximately 370 million children received school-feeding in 2012 (WFP 2013). Scaling-up and consolidating school-feeding programmes requires considerable resources and a steady flow of funds: in low-income countries, school-feeding programmes cost an average of about US $\$ 50$ per child per year (Gelli et al. 2011). Therefore, it is essential to undertake a careful assessment of its benefits and trade-offs (Alderman and Bundy 2011). Key to this assessment is an understanding of how different school-feeding implementation models compare to each other and to other interventions with similar aims and objectives, such as conditional cash transfers or scholarships. However, until now, the lack of valid methodologies to estimate overall impact across different outcomes has presented a barrier to such an assessment. In this paper, therefore, we outline two approaches that can be used to aggregate outcomes for school-feeding interventions across education, health and nutrition and other relevant social outcomes.

\section{$2 \quad$ Comparing interventions}

Comparing alternative interventions with multiple outcomes has been a long tradition in economic evaluation; this often takes the form of a cost-effectiveness analysis (CEA) or costutility analysis (CUA) (Drummond et al. 2005). CEA requires the ability to identify one single reliable and appropriate outcome measure of the intervention programmes. This may prove difficult when the programmes being investigated have multiple objectives and outcomes. A variant of CEA, cost consequence analysis, does tackle multiple outcomes. However, it does not make trade-offs between different outcomes explicit. Often, decision makers may either be implicitly making the judgement or unable to make a decision based on multiple outcomes (Drummond et al. 2005).

As mentioned above, school-feeding programmes can produce a number of outcomes, including improvements in height and weight of the pupils, increased attendance, increased attention, and better school performance (Kristjansson et al. 2007). A cost-utility analysis that employs a utility measure combining all possible outcomes is therefore more appropriate.

The utility measures used in CUA, such as quality-adjusted life years (QALYs), incorporate explicit weightings of the various outcome components of an intervention. The main challenge, in the case of school-feeding, centres on how to estimate those weightings. Two alternative approaches are proposed below.

\subsection{Quality-adjusted school days}

School-feeding outcomes are measured using very different metrics. On the one hand, some outcomes are related to learning access, or the increased quantity of school days. On the other, outcomes such as increased attention and improved cognition translate into improved quality of the learning during the attended school days.

One way of aggregating across these two dimensions is to introduce the notion of quality-adjusted school days as an overall measure of the extra school days obtained as a result of school-feeding (see Figure 1). If a child attends school more often, he/she is gaining school days, and if a child has greater learning ability, he/she is also gaining school days because fewer days are needed to learn the same material. This frees up school days for additional learning. Hence, we argue that school-feeding adds days, not only through increased attendance and reduced drop-out, but also through increased learning capacity. Thus, our approach is to focus on translating the increased 
quality of learning from school-feeding into quantity of extra days gained from enhanced learning. We propose that this extra quantity of learning days gained from school-feeding programmes can be modelled using estimates of programme impact across schooling access outcomes (e.g. enrolment, attendance and drop-out, and learning outcomes). The parameters for the model can be obtained from data from the update of the school meals review (In process, Kristjansson et al.). They may also be obtained from impact evaluations.

Figure 1: From multiple school-feeding outcomes to improved learning

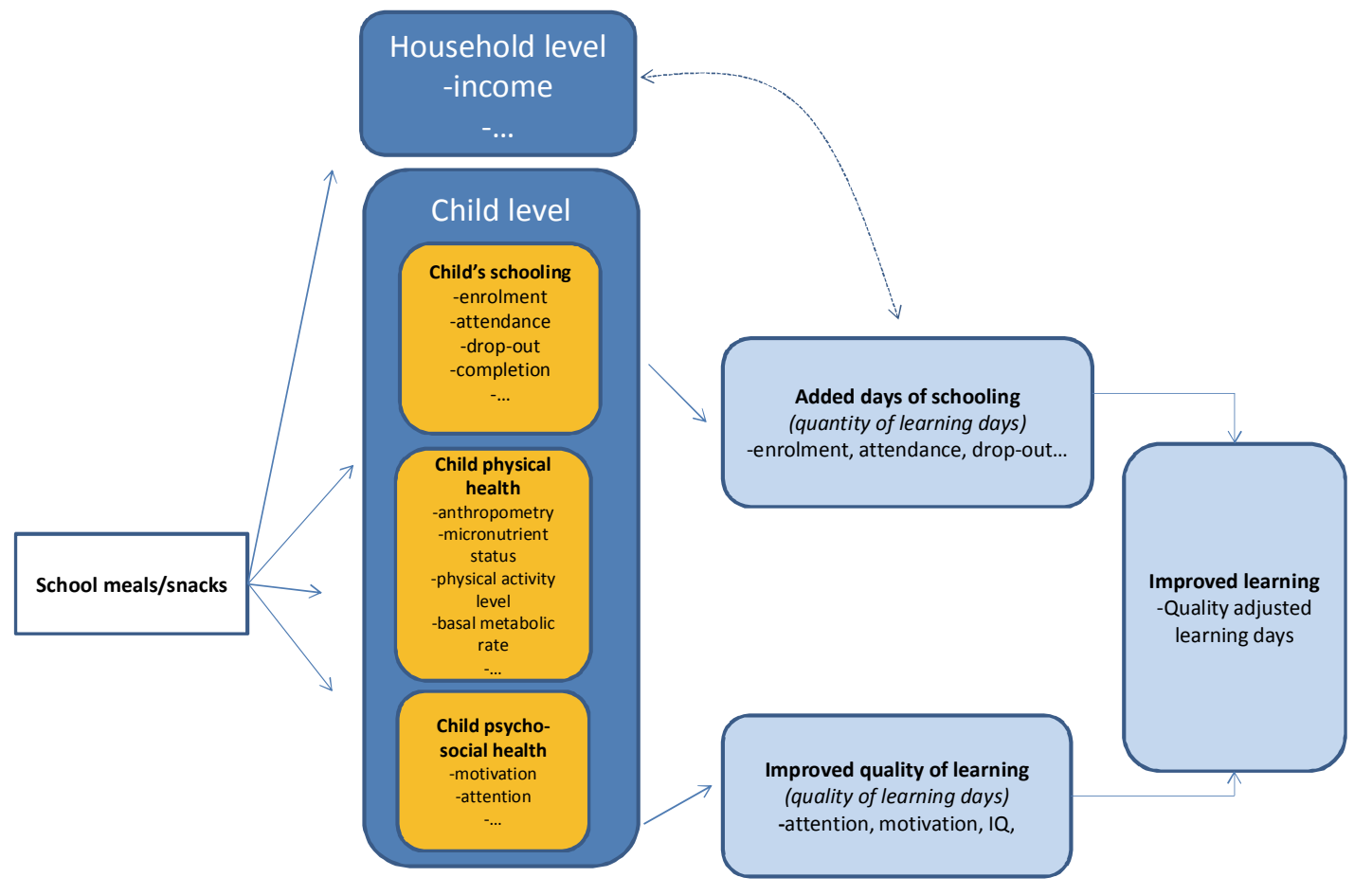

Source: Authors.

We can model learning $\left(\mathrm{L}_{\mathrm{i}}\right)$ as a function of a child's learning capacity $\left(\mathrm{c}_{\mathrm{i}}\right)$, quality of learning in school $\left(\mathrm{q}_{\mathrm{s}}\right)$ and time spent on learning in school $\left(\mathrm{t}_{\mathrm{j}}\right)$, or

$$
L_{i}=f\left(c_{i}, q_{s}, t_{i}\right)
$$

From the evidence on programme impact (Kristjansson et al. 2007), one can assume that lowincome children suffering from poor nutrition would perform more poorly than children who are better-off, all other conditions being equal. In a very simplified case, we can assume that learning is a linear function of learning time multiplied by a child's ability and a learning 'quality factor' q, with the cumulative learning in an ideal case given by the area of the triangle OAB in Figure 2. Similarly, the learning of a poor and undernourished child, who learns for fewer days and at a lower rate, is given by the area of the triangle OEF. Supposing that at the end of the school year, poor and undernourished children attended on average only 160 days (line segment OF) out of 200 days (line segment OB) of the school year due to absenteeism for reasons related to their vulnerabilities. Furthermore, following from our simplified example, these children will have learned less in the 160 days of attendance due to short-term hunger and micronutrient deficiencies. At the end of the year they may have learned an equivalent to the learning achieved by a non-disadvantaged child in far fewer e.g. 140 school days (area under triangle OIJ), 
controlling for quality of learning. In that case, one can say that the disadvantaged children attended the equivalent of 140 quality-adjusted school days.

Figure 2: Stylized learning trajectories for children learning at different rates

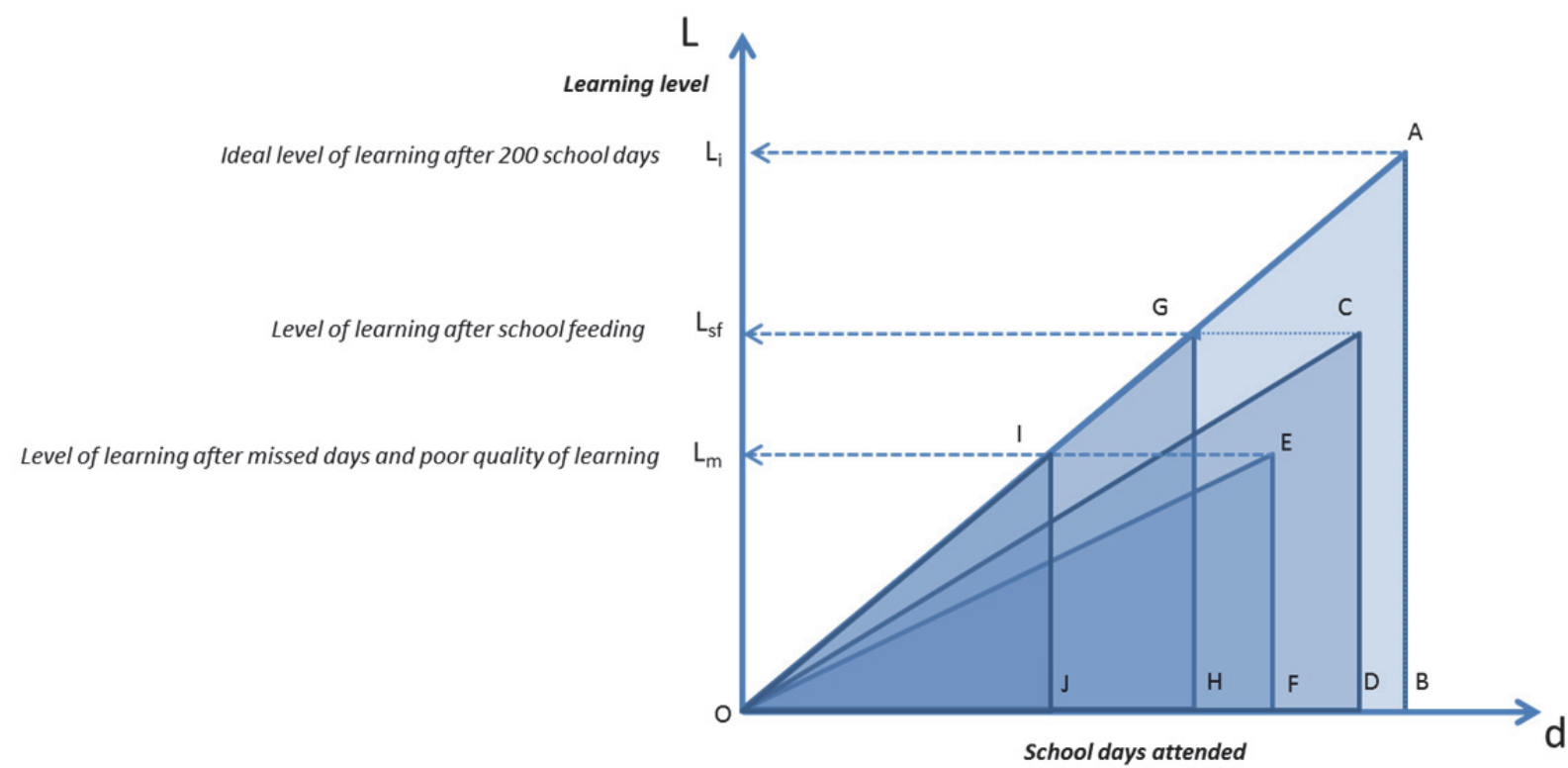

Source: Authors.

In this hypothetical case, the disadvantaged child's learning and attendance improves due to school-feeding, and he/she would gain learning days, equal to 20 school days (line segment FD) from increased attendance. He/she would also gain an equivalent of 10 more days from improved learning capacity totalling a gain of 30 quality-adjusted school days (increasing the total cumulative learning from area of triangle $O E F$ to the area of triangle $O C D)$. A non-quality-adjusted estimation would say that the children would have benefited only from the 20 days added through increased attendance. Illustratively, in terms of cumulative learning, the difference between pre- and post-school feeding would be given by the difference in areas of the two triangles (OCD-OEF) in Figure 2.

\section{Converting test scores to 'learning per day' equivalents}

To move from assessing the impact of school-feeding as 20 non quality-adjusted school days to 30 quality-adjusted school days, we require a way to convert the 'level of learning' into the number of full quality school days needed to achieve such level of learning, i.e. to learn 60 per cent of the expected learning, ' $x$ ' number of full quality school days are needed. This would be analogous to estimating the coefficient of ' $q$ ' in our model, or the slope of the line segment OA, and then multiplying this by the number of learning days.

One way of measuring levels of learning, or the expected learning, is to use standardized test scores or standardized national examinations. These types of assessments can allow comparisons by grade of the learning level achieved in different schools against a national standard. Results are usually expressed as scores or percentage achieved out of a pre-established national standard. If those scores can be reformulated in number of full quality school days needed to reach a given score, or level of learning, an estimation of the quality-adjusted school days effectively offered by a specific school can be produced. 
Developing our idealized example further, we could assume that if the national standard was equivalent to achieving 100 per cent of learning key contents, this level of achievement would imply that the student learned those contents throughout the 200 school days of a normal school year. Therefore it can be assumed that those 200 school days were 200 full quality school days because the expected learning was fully achieved (of course there is a range for this but it is not considered in the example). If a school achieves 70 per cent instead of 100 per cent of the standard, it can be inferred that the 200 school days were not full quality-adjusted school days; in practice those children benefitted from equivalent of less than 200 full quality school days. Therefore, if a relationship can be established between the level of learning and the number of days needed to achieve that level, one can say that in that school, the students only benefitted from, let's say, 140 quality-adjusted school days. It is important to reflect that in our original hypothesis, learning is a function of a child's ability, the quality of learning and the time spent on learning. For the sake of simplicity we are assuming that a child's learning ability and the child's learning time in school can be modified through school-feeding, and that these changes do not affect $\mathrm{q}$ which is a school level characteristic. Data on standardized school level test scores held in national databases, like those held in Chile, 1 could then be used to obtain estimates of the learning quality parameter $q$ whilst controlling for socio-economic characteristics within the school population.

\section{Estimating improvements in learning quality from improved health and nutrition}

Estimates of increased learning time through improved attendance from school-feeding in Randomized Control Studies indicate increases of about 4-6 school days per year (Kristjnasson, 2007). These extra days are not necessarily full quality school days, so they should be adjusted to quality school days based on the learning conditions in a given school. That quality can be estimated through the scores in the national exam, as described above. The problem of converting increased learning from school-feeding into full quality school days remains. Findings from the 2007 systematic review indicated gains in math performance, short-term cognition, as well as in on-task and classroom behaviour. We can use these estimates to gauge the size of the parameter $c$ for the increase in a child's ability. In addition, educational experts and teachers could help to estimate the number of days in which a non-disadvantaged child would need to learn what a disadvantaged child had learned in a school year. For example, the nondisadvantaged child may need 120 days to learn what a disadvantaged child would learn in 180 . This can be done through a set of questions where experts and teachers can estimate the time needed to learn a given subject by non-disadvantaged children compared to undernourished and poor children.

Once we have an estimate for $q$ and for the changes in $c$ due to poverty and hunger, we can then estimate the gains in quality-adjusted school days from a school-feeding intervention. The overall impact of school-feeding on education can be estimated and compared to alternative interventions aimed at increasing learning and attendance, such as hiring new teachers, lowering school fees, increasing learning support, or conditional cash transfers. The budgetary requirements for the different alternatives could also be estimated, providing the basis for comparisons in terms of cost-utility.

\section{Required data collection methodology}

Not all the parameters that constitute the components and the assumptions made in the description of the models outlined above are available from the literature. In particular, there are considerable uncertainties about the parameters that describe the casual pathways and

1 See http://www.agenciaeducacion.cl/simce/que-es-el-simce/ for further details 
interactions between school-feeding, health and nutrition status and improved quality of learning. Hence, we propose to gauge some of these parameters through discussion with experts on school-feeding and child development; we would also conduct an online survey of practitioners.

\section{Discussions with experts}

These discussions focus on the impact pathways between school-feeding and learning. The starting point will be the impact theory outlined in Figures 3 and 4 (Appendix 1). Guided by a summary of the evidence provided in the recent realist review (Greenhalgh et al. 2007), the indepth discussions explore the evidence and gaps in the causal pathways linking food provision to learning (see Appendix Two for some draft questions). These discussions help to establish a set of parameters characterizing each of the links in the causal pathways.

\section{Online survey for teachers and other school-feeding practitioners}

The online survey aims to learn the relative value of the different outcomes of school-feeding, attempting to associate different levels of learning, on a continuum between ideal learning and impaired learning due to poor nutrition and poverty, with gains in outcomes attributable to the school-feeding intervention. The surveyed teachers need to be well acquainted with schoolfeeding programmes. Thus, we propose a survey of teachers in countries that have had school-feeding programmes for at least ten years. Primary education is the usual target of schoolfeeding, therefore, teachers should come from that level. A random sample of teachers from two or three typical subnational regions can then be used to pilot the attributes and values identified by the experts. A sample of the survey questionnaire is included in Appendix 3.

\subsection{Method two: valuating benefits through discrete choice experiment}

The second possible method for combining the multiple outcomes of school-feeding is a Discrete Choice Experiment (DCE). DCEs have been widely and increasingly used to derive monetary values or utility scores that can combine different outcomes into a single measure (Ryan et al. 2001). These are useful in areas where a market does not exist for the good in question; school-feeding programmes in this case. The DCE approach has its theoretical base in random utility theory and consumer theory in economics, and utilises experimental design and econometric techniques (Louviere et al. 2000).

DCE is an attribute based measure of benefit, which assumes that the intervention programmes can be described by their characteristics (or attributes) and an individual's valuation depends on the levels of these attributes (Ryan and Gerard 2003). In a DCE, participants are offered a series of choice sets with different combinations of attribute levels. Responses to the individual choices made reflect the relative importance respondents place on the attributes and the trade-off that individuals make between the attributes. The latter is measured by the marginal rates of substitution (MRS) between these attributes. For example, the MRS of attribute $X_{1}$ for attribute $X_{2}$ is the amount of attribute $X_{1}$ that an individual is willing to exchange for attribute $X_{2}$. In utility theory, individuals are expected to behave rationally to maximize their utility. Therefore, the choices observed in a DCE are assumed to reveal an underlying (latent) utility function, where an individual evaluates the alternatives in each choice set and chooses the set which gives the greatest relative utility by making trade-offs between the attributes (Ryan 2008). Presented formally in mathematical forms, an individual will choose alternative choice set A over B, if:

$U\left(X_{A}, Z\right)>U\left(X_{B}, Z\right)$ 
where $\mathrm{U}$ is the individual's utility as a function of the set of attributes $\left(X_{A}\right.$ for choice set $\mathrm{A}$ and $X_{B}$ for choice set B) and the participant's socioeconomic and demographic characteristics $Z$. Econometric techniques are applied to analyse the results of the DCE based on random utility theory, where an error term is included in the utility function to represent the unobservable factors and is assumed to be randomly distributed and uncorrelated with $\mathrm{X}$ or $\mathrm{Z}$. This can be expressed formally in the formula below, an individual will choose choice set A over B if:

$V\left(X_{A}, Z\right)+\varepsilon_{A}>V\left(X_{B}, Z\right)+\varepsilon_{B}$

where $\mathrm{V}$ is the measurable component of individual utility observed from the DCE and $\varepsilon_{\mathrm{A}}$ and $\mathcal{E}_{B}$ represent the unobservable components.

By combining MRS across different attributes obtained from the DCE, overall benefits (as measured in utility scores) of different school-feeding programmes can be derived and compared across models. If a price attribute is included, the willingness to pay value as an overall monetary benefit for the intervention can also be calculated (Ryan et al. 2008).

To evaluate the benefits of the school-feeding programme using a DCE approach, all possible attributes (outcomes) of the school-feeding programme and levels assigned to each of the attributes need to be identified. Attributes describe the outcomes of the school-feeding programme, for example, improvement in weight or height, IQ scores or attendance improvement; while levels describe the possible variations of each attribute. For example, for an attribute of school attendance, possible levels may be 0 days, 0.5 days, 1 day, 1.5 days, and 2 days. The attributes and levels would be informed by evidence from the updated systematic review currently being performed by Kristjansson and her colleagues. The combination of different levels of each attribute might create a large number of possible scenarios. As this number is likely to be too large to be considered by respondents, an experimental design technique will be utilised to reduce the full factorial design (i.e. the full set of all possible combinations of attributes and levels to a manageable number (Lancsar and Louviere 2008). We would design a questionnaire with introductory text explaining the task and the DCE choice sets. As different weights may be placed over the attributes and levels depending on the type of country being considered by the respondents (low- or middle-income countries), the DCE would be conducted in two sub groups: a low income group and a middle income group. The questionnaire would undergo pretesting and piloting.

The pretesting would involve experts in a focus group setting. This will ensure that all important and relevant attributes are identified, and that the range and number of levels for each included attribute are justified and supported by evidence. The questionnaire would then be piloted in a subsample of the target population, sufficiently large enough to conduct preliminary analyses ( $\mathrm{n} \approx 30$ per group). Following the pilot DCE, the questionnaire would be refined based on feedback from the pilot DCE, and a full DCE conducted among study participants; teachers from the relevant countries. Teachers will be selected following the rationale mentioned in the preceding section. An illustrative example of the attributes and levels and the DCE questionnaire is shown in Appendix 4. 
A number of recent studies and reviews illustrate a growing evidence base on school-feeding, including a broad range of benefits for vulnerable school age children across education, health, nutrition and other dimensions. To date, however, an important gap in school-feeding evaluation centres on the fact that there is no single metric to capture the effectiveness of school-feeding combining the different, and often simultaneous, outcome. Thus, we have been unable to fully compare school-feeding with other interventions.

In this paper we have sought to develop two alternative approaches to aggregate and evaluate school-feeding programmes across different several outcomes. One approach involves the development of a DCE to derive monetary values or utility scores combining the different outcomes into a single measure. The other focuses on the notion of quality-adjusted school days as an overall measure encompassing both the increased participation and learning outcomes from school-feeding.

Pros and cons of each approach

The DCE offers a very robust method (from economic theory) to estimate and integrate utility for different benefits of school-feeding. On the other hand, it necessitates a relatively complex design in which experts and then practitioners have to be interviewed to assess utilities. The quality-adjusted school days method has the advantage of greater simplicity; its' modelling stems from existing research and relies on practitioner's opinion to convert gains in learning into school days. However, it is possible that the method used to arrive at an integrated indicator may be less robust than the one offered by DCE. Both approaches could be tried separately, allowing for comparison of results and adjustments. Both methods are subject to the limitation that they do not include the benefits observed at the household level, either those obtained through income transfer due to feeding children at school or income increase through selling merchandises to the programme (in case the family is producing them, i.e. small scale farmer). Moreover, both approaches are likely to be context and country specific, both in terms of the weightings for the different outcomes and for the standards for learning achievement. Generalizing these context specific parameters is not straightforward.

In any case, a new integrated indicator for school-feeding is achievable through the implementation of either method. When developed, they can offer a relatively easy to obtain metrics that will significantly help to compare this and other interventions that aim to foster learning. Thus, the education sector will be able to compare interventions much like the health sector has been doing for many years (Robinson 1993). This, taken together with evidence on outcomes and process from systematic and realist reviews, can inform policy makers who need to make difficult choices about allocation of scarce resources.

\section{References}

Alderman, H. and D.A.P. Bundy (2011). 'School Feeding Programs and Development: Are We Framing the Question Correctly?’ World Bank Research Observer. Washington, DC: The World Bank.

Adelman, S.W., D.O. Gilligan, and K. Lehrer (2008). 'How Effective Are Food for Education Programs? A Critical Assessment of the Evidence from Developing Countries'. Food Policy Review No. 9. International Food Policy Research Institute, Washington, DC. 
Bundy, D.A.P., C. Burbano, M. Grosh, A. Gelli, M. Jukes, and L. Drake (2009). 'Rethinking School Feeding: Social Safety Nets, Child Development, and the Education Sector'. World Bank.

Drummond, M.F., M.J. Sculpher, G.W. Torrance, et al. (2005). Methods for the Economic Evaluation of Health Care Programmes. 3rd edition. Oxford: Oxford University Press.

Espejo, F., C. Burbano, and E. Galliano (2009). 'Home-grown School Feeding: A Framework for Action'. Rome: United Nations World Food Programme.

FAO (2013). 'State of Food Insecurity in the World 2013'. Food and Agriculture Organization of the United Nations, Rome.

Gelli, A., A. Cavallero, L. Minervini, M. Mirabile, L. Molinas, and M. Regnault de la Mothe (2011). 'New Benchmarks for Costs and Cost-Efficiency for Food Provision in Schools in Food Insecure Areas'. Food and Nutrition Bulletin, 32(4): 324-32.

Gelli, A., A. Kretschmer, L. Molinas, and M. Regnault de la Mothe (2012). 'A Comparison of Supply Chains for School Food: Exploring Operational Trade-offs Across Implementation Models'. HGSF working paper. London: PCD.

Greenhalgh, T., E. Kristjansson, and V. Robinson (2007). 'Realist Review to Understand the Efficacy of School Feeding Programmes'. BMJ, 335: 858-61.

Kazianga, H., D. de Walque, and H. Alderman (2009). 'School Feeding Programs and the Nutrition of Siblings: Evidence from a Randomized Trial in Rural Burkina Faso'. Economics Working Paper Series 0908, Oklahoma State University, Department of Economics and Legal Studies in Business.

Kristjansson, E.A., V. Robinson, M. Petticrew, B. MacDonald, J. Krasevec, L. Janzen, T. Greenhalgh, G. Wells, J. MacGowan, A. Farmer, B.J. Shea, A. Mayhew, and P. Tugwell (2007). 'School Feeding for Improving the Physical and Psychosocial Health of Disadvantaged Elementary School Children'. Cocbrane Database of Systematic Reviews, Issue 1, Art. CD004676.

Lancsar, E. and J. Louviere (2008). 'Conducting Discrete Choice Experiments to Inform Healthcare Decision-making'. Pharmacoeconomics, 26: 661-77.

Leslie, J. and T. Jamison (1990). 'Health and Nutrition Considerations in Education Planning. Educational Consequences of Health Problems Among School-age Children. Food Nutrition Bulletin, 12, 191-203.

Louviere, J.J., D.A. Hensher, and J.D. Swait (2000). Stated Choice Methods: Analysis and Application. Cambridge University Press, Cambridge.

Masset, E. and A. Gelli (2013). 'Improving Community Development by Linking Agriculture, Nutrition and Education: Design of a Randomised Trial of "home-grown" School Feeding in Mali. Trials. doi: 10.1186/1745-6215-14-55.

Meeks-Gardner, J., S. Grantham-McGregor, S. Chang, J. Himes, and C. Powell (1995). 'Activity and Behavioral Development in Stunted and Non-stunted Children and Response to Nutritional Supplementation'. Child Development, 66: 1785-97.

Pollitt, E. (1995). 'Does Breakfast make a Difference in School?' Journal of the American Dietetic Association, 95: 1134.

Robinson, R. (1993). Cost Utility Analysis. BMJ, 307: 859-62.

Read, M.S. (1973). 'Malnutrition, Hunger, and Behavior. II. Hunger, School Feeding Programs, and Behavior. Journal of the American Dietetic Association, 63, 386-91. 
Ryan, M., K. Gerard, and M. Amaya-Amaya (2008). Using Discrete Choice Experiments to Value Health and Health Care. (Vol. 11). Dordrecht, The Netherlands: Springer.

Ryan, M. and K. Gerard (2003). 'Using Discrete Choice Experiments to Value Health Care: Current Practice and Future Prospects'. Applied Health Economics and Policy Analysis, 2: 55-64.

Ryan, M., A. Bate, C. Eastman, and A. Ludbrook (2001). 'Use of Discrete Choice Experiments to Elicit Preferences'. Quality in Health Care, 10 (Supplement 1): i55-i60.

Scrimshaw, N.S. (1998). 'Malnutrition, Brain Development, Learning, and Behaviour'. Nutrition Research, 18: 351-79.

Walker, S.P., S.M. Chang, et al. (2007). 'Early Childhood Stunting is Associated with Poor Psychological Functioning in Late Adolescence and Effects are Reduced by Psychosocial Stimulation'. Journal of Nutrition, 137(11): 2464-69.

WFP (2013). State of School Feeding Worldwide 2013. Rome: World Food Programme.

Worobey, J. and H.S. Worobey (1999). 'The Impact of a Two-year School Breakfast Program for Preschool-aged Children on Their Nutrient Intake and Pre-academic Performance. Child Study Journal, 29, 113-31. 


\section{Appendix 1: Impact theory for school-feeding}

Figure 3: A model tracing school-feeding impact pathways leading to educational goals. The main determinants of schooling and learning are child characteristics, schooling costs, households' characteristics and school quality. Children do not participate in schooling for different reasons; at the household level, it is often a trade-off between the costs and benefits of schooling that determine whether a child will go to school or not.

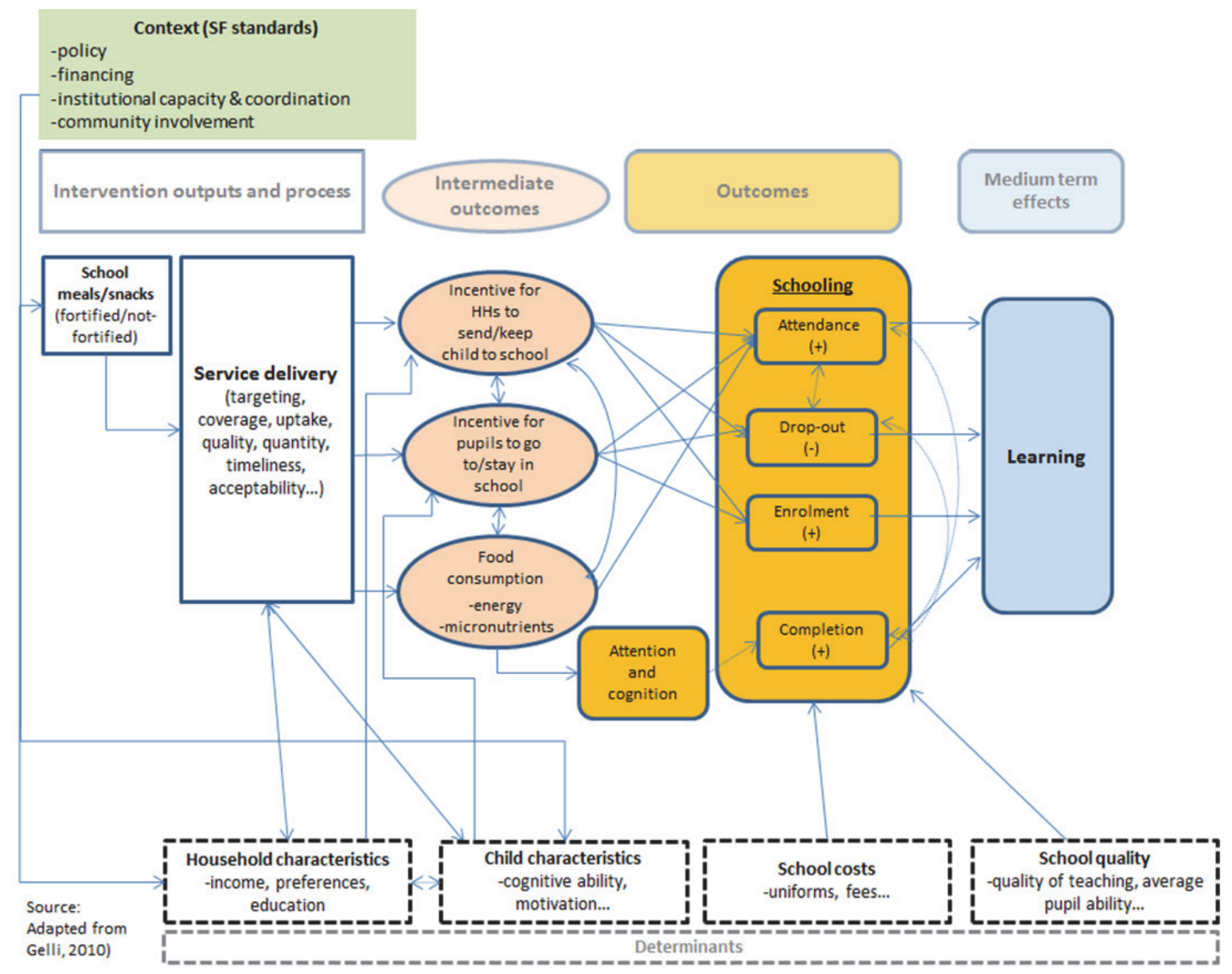

Source: Masset and Gelli (2013). 
Figure 4: Programme theory of impact on nutrition. The nutritional impact is mediated by the extent of food substitution effects within the household, and the use of the energy intake by the child and her siblings. The reduction in malnutrition via diet diversification and the absorption of micronutrients in the body can have direct effects on cognition. Better-nourished children may learn better while in class and outside class.

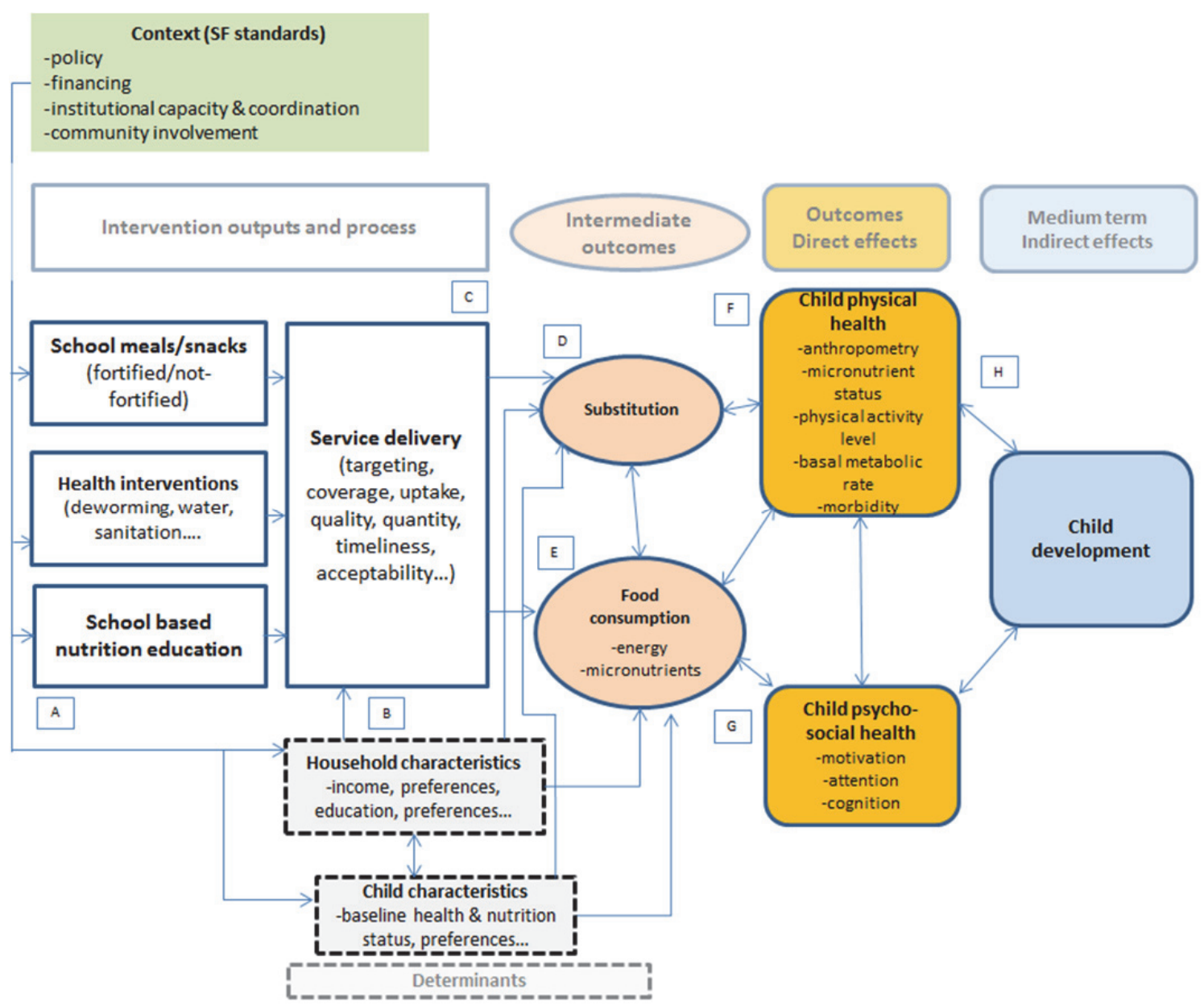

Source: Masset and Gelli (2013). 


\section{Appendix 2: Discussions with experts to verify pathways between school feeding and learning}

The purpose of these discussions is to verify the connections between controlling short-term hunger/micronutrient deficiencies and the increase in learning capacity. The starting point is the impact theory outlined in Figures 3 and 4 (Appendix 1). Guided by a summary of the evidence provided in the recent realist review (Greenhalgh et al. 2007), the in-depth discussions will explore the evidence and gaps in the causal pathways linking food provision to learning.

[Interviewer]: Validating the programme theory: This section will introduce the programme theory of schoolfeeding, running through the main impact pathways for education and nutrition (Figures 3 and 4).

These figures summarize some of the potential pathways for school-feeding impact we would like to review them together and obtain your feedback to validate these pathways. We would like to start the discussion by exploring these impact pathways.

- In terms of the potential impact of providing school-feeding on children's physical health outcomes in Figure 4, how will this influence a child's learning capacity in the classroom?

- Probe both direct and indirect effects

- In terms of the potential impact of providing school-feeding on children's pyscho-social health outcomes in Figure 4, how will this influence a child's learning capacity in the classroom?

- Probe both direct and indirect effects

- Probe how the effect is potentially conditional on the quality of the service delivery

Ganging effect sizes: This section will be used to discuss the possible effect sizes across the different pathways that lead to enhanced learning capacity.

- In terms of the potential impact of providing school-feeding on children's physical health outcomes in Figure 4, what size of effect could we expect on a child's learning capacity in the classroom?

- Probe how the effect is potentially conditional on the quality of the service delivery

- In terms of the potential impact of providing school-feeding on child pyscho-social health outcomes in Figure 4, what size of effect could we expect on a child's learning capacity in the classroom?

- Probe how the effect is potentially conditional on the quality of the service delivery 


\section{Appendix 3: Survey of practitioners}

The survey questions will be used to estimate the relationship between learning capacity and time needed to achieve a given learning objective. The survey will be designed to explore some hypothetical scenarios involving 'standardized' learning levels and learning rates. A set of draft questions are included in the following section, exploring this issue from three complementary perspectives.

Imagine for instance, a student with a full (100 per cent) learning capacity may need to attend at least 90 per cent of the school days to learn all the scholastic objectives planned for one year. A student whose learning capacity is 80 per cent of the normal capacity may need to attend at least 10 per cent more school days than a normal student to reach the expected level of learning. A student whose learning capacity is 70 per cent may need to attend at least 25 per cent more school days; a student whose learning capacity is 60 per cent may need to attend at least 40 per cent more, and so on and so forth.

Based on your own experience as school teacher please complete the following questions:

1. Learning capacity and learning time

a. A student whose learning capacity is 100 per cent (normal capacity) would need at least to attend xx per cent of the learning time (a school year).

b. A student whose learning capacity is 90 per cent of the normal capacity would need xx per cent of more learning time.

c. A student whose learning capacity is 80 per cent would need xx per cent of more learning time.

d. A student whose learning capacity is 70 per cent would need xx per cent of more learning time.

e. A student whose learning capacity is 60 per cent would need xx per cent of more learning time.

f. A student whose learning capacity is 50 per cent would need xx per cent of more learning time.

2. Mild improvements in learning capacity and reductions in learning time

a. A special intervention has increased the learning capacity of student whose capacity was 90 per cent of normal learning by 10 points. Thanks to the improved learning capacity, the student may need xx per cent less learning time.

b. A special intervention has increased the learning capacity of student whose capacity was 80 per cent of normal learning by ten points. Thanks to the improved learning capacity, the student may need xx per cent less learning time.

c. A special intervention has increased the learning capacity of student whose capacity was 70 per cent of normal learning by ten points. Thanks to the improved learning capacity, the student may need xx per cent less learning time. 
d. A special intervention has increased the learning capacity of student whose capacity was 60 per cent of normal learning by ten points. Thanks to the improved learning capacity, the student may need xx per cent less learning time.

e. A special intervention has increased the learning capacity of student whose capacity was 50 per cent of normal learning by ten points. Thanks to the improved learning capacity, the student may need xx per cent less learning time.

3. Significant improvements in learning capacity and reductions in learning time

a. A special intervention has increased the learning capacity of student whose capacity was 80 per cent of the normal learning by twenty points. Thanks to the improved capacity, the student may need xx per cent less learning time.

b. A special intervention has increased the learning capacity of student whose capacity was 70 per cent of the normal learning by twenty points. Thanks to the improved capacity, the student may need xx per cent less learning time.

c. A special intervention has increased by twenty points the learning capacity of student whose capacity was 60 per cent of the normal learning. Thanks to the improved capacity, the student may need xx per cent less learning time.

d. A special intervention has increased by twenty points the learning capacity of student whose capacity was 50 per cent of the normal learning. Thanks to the improved capacity, the student may need xx per cent less learning time. 


\section{Appendix 4: Illustrative example of DCE to be used in focus group discussion with experts}

The attributes and levels for designing a DCE questionnaire will be compiled in a table (e.g. Table 1) and pre-tested among experts to ensure all relevant attributes and levels are identified and are appropriate.

Table 1: Illustrative example attributes and levels of pre-school immunization programmes for use in the DCE

\begin{tabular}{lll}
\hline Attribute & Levels \\
\hline 1. Weight gain per month & a. $0.03 \mathrm{~kg}$ \\
& b. $0.05 \mathrm{~kg}$ \\
& c. $0.08 \mathrm{~kg}$ \\
\hline 2. Height gain per month & a. $0.05 \mathrm{~cm}$ \\
& b. $0.10 \mathrm{~cm}$ \\
\hline 3. Improved school attendance per month & c. $0.15 \mathrm{~cm}$ \\
\hline \multirow{2}{*}{$\quad$ Increased test scores per year } & a. 0.5 day \\
& b. 1 day \\
& c. 2 days \\
\hline $5 . \quad$ Costs per child per year & a. 0 \\
& b. 0.5 \\
& c. 1.0 \\
\hline
\end{tabular}

Source: Authors.

Through experimental design technique, the combination of different levels from each attribute will be reduced to a manageable number of scenarios and the scenarios will be paired to produce the DCE questionnaire. This will be piloted among a selection of the target population; teachers from both low- and middle-income countries. An example of the scenario pair is shown in Table 2.

Table 2: Illustrative scenario pair to be used in the discrete choice experiment

\begin{tabular}{|c|c|}
\hline Scenario A & Scenario B \\
\hline 1. Weight gain of $0.03 \mathrm{~kg}$ per month on average & 1. Weight gain of $0.05 \mathrm{~kg}$ per month on average \\
\hline 2. Height gain of $0.10 \mathrm{~cm}$ per month on average & 2. Height gain of $0.15 \mathrm{~cm}$ per month on average \\
\hline $\begin{array}{l}\text { 3. An increase of } 1 \text { days on school attendance per } \\
\text { month on average }\end{array}$ & $\begin{array}{l}\text { 3. An increase of } 2 \text { days on school attendance per } \\
\text { month on average }\end{array}$ \\
\hline $\begin{array}{l}\text { 4. An increase in test score of } 0.5 \text { point on average per } \\
\text { year }\end{array}$ & $\begin{array}{l}\text { 4. An increase in test score of } 1 \text { point on average per } \\
\text { year }\end{array}$ \\
\hline 5. The programme costs US\$60 per child per year & 5. The programme costs US $\$ 100$ per child per year \\
\hline
\end{tabular}

Source: Authors. 